\title{
Producción sostenible de pollo de engorde y gallina ponedora campesina: revisión bibliográfica y propuesta de un modelo para pequeños productores Sustainable production of broiler chicken and laying hen: bibliographical review and proposal of a model for small producers
}

\author{
Diana Milena Soler F. \& Jorge Armando Fonseca C. \\ dimisofo@gmail.com, jorge.fonseca@unad.edu.co \\ Universidad Nacional Abierta y a Distancia (UNAD) \\ Escuela de Ciencias Agrícolas, Pecuarias y del Medio Ambiente (ECAPMA) \\ CEAD Tunja, Colombia
}

Resumen.- La producción campesina de pollo de engorde y gallina ponedora a nivel mundial es variada, siendo los países en vía de desarrollo aquellos que más producciones de este tipo presentan. Estas explotaciones de traspatio, juegan un rol importante ya que aseguran el autoconsumo de productos proteicos y una economía de subsistencia a las familias pobres. Debido a que en el departamento de Boyacá son pocos los estudios técnicos y científicos sobre estos sistemas extensivos, este trabajo tuvo como objetivo general establecer por medio de revisión bibliográfica el estado de arte mundial, nacional y regional de la producción de pollo de engorde y gallina ponedora alternativa, y como objetivos específicos, hacer un análisis de los diferentes manejos y propuestas y plantear un modelo de producción que se adapte a las necesidades de los pequeños productores. Los resultados del estado de arte mundial arrojaron que todos los países presentan explotaciones campesinas variadas, pero no se observa un camino claro hacia la comercialización de estos productos avícolas campesinos, reconocidos por su inocuidad y calidad de nutrientes. En algunos municipios de Boyacá, estos sistemas productivos campesinos presentan utilidades y rentabilidades favorables, debido a los reducidos costos de producción por la introducción de subproductos de cosechas y materiales reciclables, además no presentan impactos ambientales significativos; sin embargo, el manejo sanitario es deficiente y la alimentación animal empieza a depender de alimentos concentrados.

Palabras clave: gallina ponedora, modelos productivos, pequeños productores, pollo de engorde, producción sostenible, sistemas campesinos.

\begin{abstract}
The peasant production of broiler chicken and laying hens in the world is wide, being the developing countries which most productions of this type arise. These backyard holdings play an important role as they ensure the consumption of protein products and a subsistence economy to poor families. Due to the low number of technical and scientific studies on these extensive systems in the department of Boyacá, this work aimed to establish by general literature review the world, national and regional state of the art in the production of broiler chicken and alternatively laying hen, and as specific objectives, to produce an analysis of the different managements and plans and propose a production model that suits the needs of small producers. The results of the world's state of the art showed that all countries have a variety of peasant farms, but there is a clear path to commercialization of these poultry farming products, renowned for their safety and quality of nutrients. In some municipalities in Boyacá, these farmers have favorable production systems and yields earnings due to the reduced production costs by the introduction of crop products and recyclable materials, and also have no significant environmental impacts, however, health management is poor and animal feeding starts to rely on concentrated foods.
\end{abstract}

Keywords: laying hen, production models, small producers, broiler chicken, sustainable production, farming systems. 


\section{Introducción}

La confianza en la seguridad de los alimentos producidos de forma intensiva, tiene a los consumidores y en especial a los europeos, tras los escándalos ocurridos desde el año 1996, así como el reconocimiento por parte de las autoridades británicas de la relación entre la Encefalitis espongiforme bovina y la enfermedad de Creutzfeldt Jakob, los pollos con dioxinas en Bélgica (1998), la utilización de lodos de depuración de residuos de mataderos en la alimentación animal en Francia y la creciente información sobre los niveles elevados de pesticidas y antibióticos en los productos finales (vegetales y animales), han contribuido a crear la duda social sobre la integridad de los sistemas tradicionales de la producción agrícola y pecuaria (Torres 2002).

Las grandes industrias de producción animal en confinamiento, pueden producir cantidades enormes de desechos que son arrojados al medio ambiente, por ejemplo la explotación comercial de un millón de ponedoras genera anualmente excretas que contienen 750 toneladas de nitrógeno y 150 de fósforo, lo cual ha sido criticado por la sociedad y los investigadores conservacionistas (Turner 1999).

La pobreza a nivel mundial y la desnutrición de niños y ancianos que se ve en los países menos desarrollados (en el 2002 existían 221 millones de latinoamericanos pobres, de los cuales 97 millones no contaban con los recursos necesarios para cubrir una canasta básica de alimentos, Martínez 2005), deben ser mitigadas a través de propuestas de producciones económicas, de fácil manejo, poco dependientes de insumos externos costosos, que aporten seguridad alimentaria a las familias de bajos recursos, y sobre todo, que aprovechen los recursos de las fincas sin traer consecuencias de contaminación al medio ambiente.

Para lograr lo anterior, nuestra sociedad debe cambiar la forma de cultivar y explotar los re- cursos naturales y animales, promover la producción alternativa que en la actualidad han tomado gran importancia en países como España, Estados Unidos, Costa Rica, Venezuela, entre otros, países que están creando conciencia en los productores, promoviendo la conservación de sus recursos naturales e inculcando que los animales sean explotados en ambientes más naturales y menos confinados, incentivando el bienestar animal que se verá reflejado en la calidad de los productos y en la disminución de los costos de producción.

Colombia, país rico en recursos naturales y costumbres étnicas en cría de animales, considera indispensable la sostenibilidad de la producción, integrar sistemáticamente los recursos suelo - planta - animal, y enfatizar en una producción animal más sana, con bienestar para todos los integrantes de la cadena y rescatar la genética criolla de nuestros animales, además, de reforzar e impulsar la seguridad alimenticia de las familias menos favorecidas.

Esta situación es más imperante para el departamento de Boyacá, debido a que muchas de las costumbres de producción no se han sistematizado y se han ido perdiendo a medida que los sistemas productivos han evolucionando y adoptado diversas tecnologías diferentes a las de nuestros antepasados.

Por este motivo, el presente trabajo de investigación tuvo como objetivo establecer por medio de revisión bibliográfica el estado actual de la producción de pollo de engorde y gallina ponedora a nivel global y en Colombia, así como hacer un análisis de los diferentes manejos y propuestas en el departamento de Boyacá para plantear un modelo de producción que se adapte a las necesidades de los pequeños productores.

\section{Materiales y métodos}

En primera instancia, se delimitó el tema de acuerdo a la problemática encontrada, a partir 
de la cual se inició la indagación, recopilación y análisis de fuentes secundarias que ayudaron a la conformación del estado actual de la situación mundial y nacional.

Adicionalmente, con el fin de hacer nuevos aportes al tema, sobre todo en el ámbito regional (Boyacá) se realizaron visitas a unidades productivas campesinas de los municipios de Duitama, Santa Rosa de Viterbo y Tibasosa. Con diálogos a los miembros de las familias, se recolectó información sobre las costumbres de cría y rentabilidad de los sistemas de pollo de engorde y gallina ponedora campesina. Finalmente se realizó la triangulación, análisis y realización de un modelo productivo adaptable a las condiciones regionales.

\section{Resultados}

Situación mundial de la producción alternativa de pollo de engorde y gallina ponedora

China: país considerado como el segundo productor de productos cárnicos después de Estados Unidos, destacándose la producción de cerdo y huevos; a pesar de considerar la producción intensiva de aves en etapa de infancia en este país, ya que sólo posee 10 años de historia, ha tenido un extraordinario crecimiento y desarrollo, como indicio de la abundancia y gran fuerza de estos sistemas de producción.

Estas producciones rurales estaban a cargo de las amas de casa; los números de animales criados no eran mayores a 200 y su alimentación se basaba en arroz y cereales de las cosechas; la lucha contra la intensificación de estas producciones no ha sido en vano, en el 2004 sólo el $2 \%$ de la producción de huevos y carne provenía de aves criadas en zonas rurales, esto debido a los controles rigurosos sobre la gripe aviar (Chen et al. 1997).

Unión Europea: la oferta de productos naturales en producciones de la Unión Europea ha crecido a una tasa promedio del $25 \%$ en los últimos 10 años, así mismo la superficie dedicada a la agricultura ecológica se ha triplicado en las últimas dos décadas. Desafortunadamente la mayoría de los cultivos agrícolas orgánicos no se destinan para consumo animal, lo que ha limitado la explotación ecológica de animales o en producciones alternativas con estos requerimientos; sin embargo, países como Australia, España y Francia, producen diversas especies (bovinos, ovinos, caprino, aves, porcinos) como explotaciones ecológicas.

Las características de las explotaciones ecológicas, en el caso de aves, consisten en la elección de estirpes ponedoras semipesadas de plumas rojas, las cuales se introducen al sistema ecológico al alrededor de las 14 y 16 semanas de vida; las instalaciones utilizadas en la mayoría de los casos son casetas móviles y edificios fijos, y se maneja una densidad animal no mayor a 6 gallinas $/ \mathrm{m}^{2}$; en cuanto a la luz natural, ésta podrá complementarse con medios artificiales para obtener un máximo de 16 horas de luz diariamente y descanso nocturno continuo sin luz artificial de al menos 8 horas (Banco 2004).

Además, en estos países recomiendan que las casetas o el pastoreo, se realicen en terrenos con árboles, ojalá con frutales y matorrales de bajo crecimiento como cercas vivas; es conveniente efectuar una rotación de gallinas por diferentes lugares cada 10 semanas. La alimentación incluye granos y otros ingredientes mezclados en diversas proporciones, como ejemplo se cita el maíz, trigo y cebada en una proporción 11:10:4 administrada a discreción a razón de $30 \mathrm{~g}$ por gallina/día, y harina de productos cultivados en la propia finca. No se deben administrar proteínas animales en la dieta (Banco 2004).

Las anteriores recomendaciones de alimentación para gallinas en explotaciones alternativas, suponen un costo superior, debido a que en la mayoría de los casos el costo del pienso 
ecológico es de 0,42 euros/kg mientras que el elaborado con productos de matadero cuesta 0,14 euros $/ \mathrm{kg}$. Esto aumenta el costo de los productos como huevo y carne ofrecidos a los consumidores (Torres 2002).

Estados Unidos: en este país tan sólo un $2 \%$ de las aves domésticas para la producción de carne y huevos se mantiene en algún tipo de sistema alternativo; los pequeños productores crían aves "libres en pasturas" (free-range) como parte de una granja diversificada, las cuales quieren tomar ventaja del estiércol de las aves para mejorar las pasturas para los rumiantes, y aprovechar que las aves escarban las boñigas de excremento de otros ganados para consumir larvas y reducir las moscas y problemas de parásitos en otras especies.

En Estados Unidos, se emplean diversos sistemas de producción de aves en pastoreo como patio, corral, campo de malla movible, campo de malla estacionaria, en pastura, colonia ( $\mathrm{Fa}$ nático 2002), con densidades muy bajas (1 gallina por cada $10 \mathrm{~m}^{2}$ ) las cuales dependen del terreno y de la estación del año; en este sentido, en épocas de invierno, las camas profundas se utilizan para el buen manejo del estiércol cuando el pasto no crece, la cama profunda se realiza para capturar los nutrientes del estiércol de pollo por medio de un "banco de carbono" y luego ser esparcido en la granja cuando se necesite (Turner 1999). La alimentación de estas aves consta de alimento concentrado y suplementos de hortalizas, avena como el alimento verde, trébol ladino, alfalfa, trébol blanco de Nueva Zelanda (y otros tréboles), pastos tales como el Ballico (Rye grass) perenne y anual y el pasto sudan, mijo (millet) y sorgo (Barrantes 2005).

América Latina: en los países subdesarrollados, la cría doméstica tradicional de animales utiliza pocos insumos y es básica para la seguridad alimentaria; en este caso, la avicultura en el patio de casa y al aire libre representa hasta del $70 \%$ del total de la producción de huevos y carne de aves en los países de bajos ingresos y con déficit de alimentos. La diversidad es alta, ya que en muchos países y regiones las costumbres de cría son diferentes.

Cuba es uno de los países donde el 90\% de las familias rurales con animales de traspatio posee gallinas, y el promedio de gallinas criadas por familia rural varía de 8 a 20 según la región y la disponibilidad de recursos. En la mayoría de los casos, las aves se tienen en pastoreo libre sin algún tipo de instalaciones; el alimento que se les provee a las aves se compone de desechos de casa (cualquier cosa comestible que se encuentre en el ambiente inmediato) y pequeñas cantidades de granos como suplemento (mayormente maíz), los cuales son administrados por el 70\% de los criadores (Pérez \& Villa 2002).

La alimentación de las aves en este país depende de la disponibilidad del grano en la casa, la estación del año, los ciclos de cosechas, los ciclos vitales de insectos y otros invertebrados, lo cual indica que las dietas de estos animales no son balanceadas, constantes, nutritivas y suficientes para aumentar la productividad de los animales criados bajo este sistema. Se ha notado una elevada dependencia entre la suplementación del alimento y la aparición de procesos patológicos, mayormente respiratorios, parasitarios, eventos de cólera aviar, enterobacteriosis y coccidiosis en los lotes de aves por la pobre nutrición.

Cuba tiene baja producción de aves (46 a 56 huevos/año) y el inicio de la puesta de las gallinas es tardía, debido a diversas causas como condiciones inferiores de alimentación, influencia de la estación del año en que se incuban los huevos sobre el inicio de la puesta, mortalidad, entre otros (Pérez \& Villa 2002).

Chile ha sido pionero en la conservación de razas autóctonas gracias a las investigaciones sobre la gallina "araucana de huevos azules", raza que ha demostrado poseer una capacidad de adaptación al medio, buenos rendimientos productivos y un interesante aporte a la economía familiar campesina (Moya 2004). 
Los huevos azules, se han caracterizado por ser más resistentes debido al grosor de su cascara y poseer mayor contenido de proteínas, glucosa y carotenos que los huevos castaños, hecho que ha incentivado la realización de programas campesinos de producción alternativa, donde las aves se crían de forma semi-intensiva, en corrales de pastoreo cercados, con densidades de 6 gallinas por $100 \mathrm{~m}^{2} \mathrm{y}$ dentro del corral 2 aves / $\mathrm{m}^{2}$ (Moya 2004).

En estos sistemas chilenos no se utilizan ni recomiendan alimentos concentrados o preparados comerciales, alimentos transgénicos, antibióticos u hormonas; la alimentación de las aves está basada en productos energéticos del tipo cereales (maíz, cebada, avena, trigo), otros energéticos del tipo subproductos como harinilla y afrechillo. $y$ alimentos proteicos de origen vegetal como afrechos de maravilla o afrecho de soya (sólo en el caso que sea cultivada por los propios campesinos y se asegure que no es material genéticamente modificado); los suplementos que se incorporan a la alimentación de las aves se basan en conchuela o "cáscara de huevo molida y tostada”, sobras de cocina, forraje verde a voluntad y sal común como aporte de cloro y sodio. Todo lo anterior dependiendo de las disponibilidad en las mismas fincas campesinas.

En Costa Rica se han diseñado y evaluado sistemas de producción de huevos con gallinas bajo pastoreo en el trópico húmedo bajo ( $56 \mathrm{msnm}$, temperatura media anual de $25,1^{\circ} \mathrm{C}$ y humedad relativa de $90,4 \%$ ) donde el pastoreo se basa en casetas móviles construidas con recursos de bajo costo o propios de las fincas y de los espacios disponibles en las fincas en relación a los niveles alcanzados en la adaptabilidad, productividad y calidad de los huevos; las aves permanecen en pastoreo desde las 7 am hasta las $6 \mathrm{pm}$ y con suministro de $3 \mathrm{~kg} /$ día de alimento concentrado dentro de las mismas casetas (Muñoz 2002).

En estos sistemas de producción avícola, se ha observado una baja morbilidad, mortalidad y canibalismo debido al poco estrés que manejan las aves, aumentando la producción gradualmente de acuerdo a la madurez del ave y la calidad del huevo. La línea Isa Brown es la preferida para este tipo de sistemas de cría, ya que presenta mayores niveles de productividad, mejor calidad y resistencia del huevo, menores valores de colesterol en el mismo y consume menos alimento concentrado para la producción de huevos; sin embargo, requiere de planes sanitarios que muchas veces no son instaurados por los campesinos (Muñoz 2002).

México ha sido un país que ha estudiado el comportamiento productivo de pollo de engorde en pastoreo con el fin de producir alimento sano mientras se fertilizan los terrenos; para ello se han diseñado sistemas de producción de bajo costo con jaulas móviles de madera de $3 \mathrm{~m}$ x $3 \mathrm{~m}$ y $60 \mathrm{~cm}$ de alto, las cuales se van rotando en una superficie de $180 \mathrm{~m}^{2}$ para una población de 100 pollos/jaula. El potrero de pastoreo para este tipo de sistema de cría, debe estar sembrado con pastos como alfalfa y rye grass para mejorar la alimentación de las aves. El ciclo de producción termina en 60 días con pesos promedios de las aves de $1,8 \mathrm{~kg} /$ pollo (Carballo 2000).

En México, las aves de postura de la línea Rhode Island son manejadas igual que los pollos de engorde, en las jaulas se alojan 40 gallinas, las cuales son rotadas diariamente en la mañana, momento en el que se les suministra alimento, agua y se recogen los huevos; con este sistema de cría se alcanza un pico de producción de postura del $80 \%$; estos sistemas se hacen económicos y rentables a medida que las aves disminuyen su consumo de grano y aumentan en consumo de pasto y pequeños insectos (Posada \& Sánchez 2005).

En Colombia aunque las producciones de traspatio son las más difundidas en las regiones y son instauradas por pequeñas familias de estratos bajos, no se conocen encuestas sobre las mismas, a diferencia de las encontradas para las explotaciones intensivas. 
Algunos estudios se han desarrollado en varias regiones del país, los cuales han investigado la productividad de las aves en sistemas de pastoreo rotacional con la utilización de diversos alimentos propios de las zonas y de las fincas campesinas. Las estirpes predilectas son la Hy Line Brown para las aves de postura y la Ross para el pollo de engorde.

En Colombia, los alimentos más utilizados en la cría de aves en la región caribe es el maíz trillado, alimento concentrado, lombriz roja californiana, maní forrajero (Aranchis pintoi), maíz amarillo, hoja de quiebrabarrigo (Trichantera gigantea), yuca con cáscara, plátano pineo con cáscara (Musa paradisiaca), soya integral cocida y pastos comunes, todos ellos con diversos porcentajes de inclusión en la dieta de las aves (FAO 2002).

Los resultados que se han obtenido en la región Caribe con estos sistemas avícolas cuando el alimento alternativo reemplaza hasta en un $50 \%$ al alimento concentrado comercial, son el mantenimiento prolongado de los porcentajes de producción (en comparación a los sistemas intensivos, se producen 200 huevos por gallina/año) y la poca alteración del peso del huevo y de las aves, al mismo tiempo que se baja el consumo de alimento concentrado y se disminuyen los costos de producción (FAO
2002). Desafortunadamente en este estudio no se registraron datos sobre conversión alimenticia, consumo diario de las aves, peso y edad de la primera postura, duración de la misma, entre otros, para llevar a un análisis más detallado de la sostenibilidad y rentabilidad de este sistema.

En Colombia, un sistema en pastoreo exitoso realizado en el centro del país denominado "Gallina feliz", ha representado una buena alternativa para la producción de huevo en semiconfinamiento y pastoreo. En este sistema las aves son mantenidas en corrales de postura fija y cuatro corrales de pastoreo en donde las aves se rotan cada 7 días; se mantiene una densidad de población no mayor de 8 aves $/ \mathrm{m}^{2}$ en el corral de postura y 4 aves $/ \mathrm{m}^{2}$ en el corral de pastoreo (Vargas, comunicación personal 5 de septiembre del 2007).

En este sistema, la dieta se basa en el consumo de forraje kikuyo $\mathrm{u}$ otros pastos sembrados en el predio y alimento concentrado dependiendo de la etapa de producción; este último se disminuye gradualmente a medida que las aves aumentan el consumo de pastos o forrajes. En este sistema la productividad es igual a la de los sistemas de jaula (Figura 1), y los costos de producción pueden ser reducidos, al mismo tiempo que se le da un valor agregado a los huevos obtenidos de las aves manejadas bajo estos

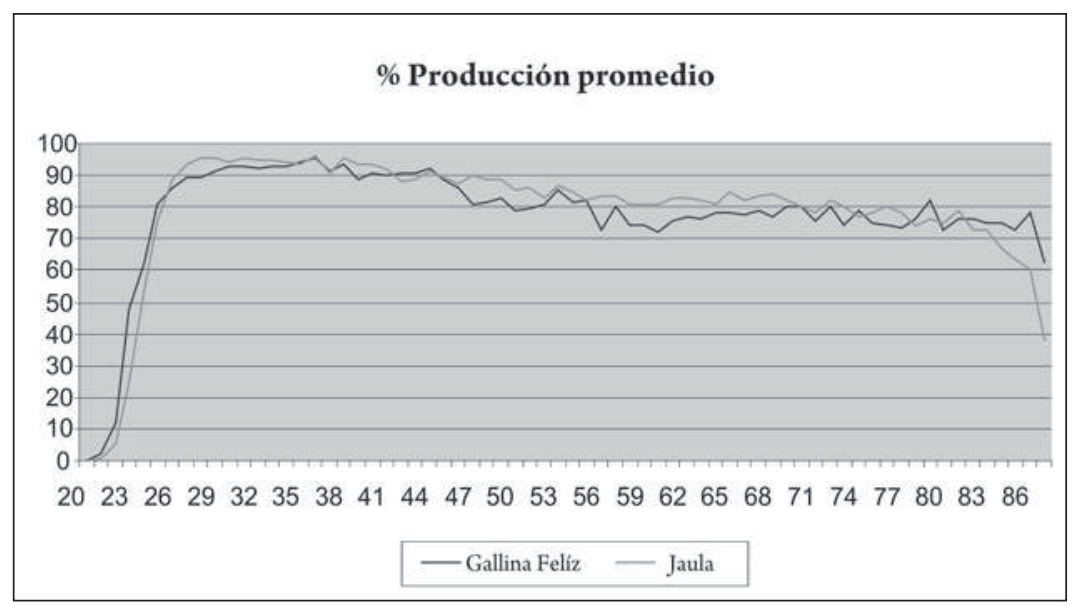

Figura 1. Producción promedio de huevo de gallina en pastoreo y jaula del programa "Gallina feliz". 
sistemas (30\% mayor que los huevos convencionales) (Vargas, comunicación personal 5 de septiembre del 2007).

En Colombia, otros sistemas de pastoreo se han evaluado, con la inclusión de diversos alimentos y recursos dentro de los potreros de pasturas de las aves, como el lombricultivo, maíz quebrado, maíz pregerminado, azola, buchón y ramio. Los resultados de estos estudios muestran que las aves a las que se les incluye en la dieta mayores cantidades de maíz, azola y pastoreo, presentan huevos de mayor tamaño y mejores ganancias de peso; además, el bienestar animal en este tipo de explotaciones es excelente, debido a la libre expresión del comportamiento animal (Cuellar \& Garcia 2007).

Caracterización de la producción de pollo de engorde y gallina ponedora en el departamento de Boyacá

Las explotaciones animales de Duitama, Santa Rosa de Viterbo y Tibasosa son pequeñas, cuentan con diversas especies animales, y están asociadas con algún tipo de cultivo de hortalizas, cereales, tubérculos, frutales, entre otros. Las aves hacen parte fundamental de estas producciones.

En el sistema avícola de traspatio manejado en el departamento de Boyacá, la línea de ponedoras más utilizada es la Isa Brown, y la línea Ross es la que más predomina en los sistemas campesinos de pollo de engorde. Estos sistemas han sido llevados por generaciones familiares, las cuales criaban en épocas pasadas a las aves sin algún tipo de instalaciones (animales sueltos en el predio), sin suplementos alimenticios aparte del poco maíz que se les suministraba, lombrices y forraje que los animales conseguían en su pastoreo; pero debido a la necesidad de conseguir recursos económicos para el sostenimiento de las familias, el manejo de estos animales ha cambiado, reemplazando el pastoreo por el confinamiento lo que les ha traído a las familias aumento en la producción avícola y mayor manejo y control sobre los animales. Sin embargo, estos datos son difíciles de cuantificar, debido a que las familias campesinas no llevan registros productivos ni sanitarios de sus producciones.

Características de la producción de pollo de engorde: debido a la poca extensión de tierra que poseen la mayoría de las fincas, los pollos son criados en corrales con dimensiones reducidas y capacidad para albergar pocas aves (Tabla 1); estos corrales están construidos con materiales reciclables como madera, cartón, plásticos, entre otros, y están cerca de las viviendas humanas o dentro de cuartos que antes eran utilizados para el almacenamiento de productos.

Otros implementos utilizados en la cría de pollos de engorde campesino son los comederos y bebederos, construidos por los miembros de las familias en diferentes materiales dependiendo de los recursos de cada una de las fincas; estos van desde tubos PVC a lo largo del galpón, botellas de gaseosa y cajones en madera, fáciles de retirar, asear y desinfectar.

Tabla 1. Dimensiones, número de aves alojadas y densidad animal de las instalaciones de pollo de engorde en municipios de Boyacá, Colombia.

\begin{tabular}{cccc}
\hline & $\begin{array}{c}\text { Dimensión de las } \\
\text { Instalaciones }\left(\mathrm{m}^{2}\right)\end{array}$ & $\begin{array}{c}\text { Número de } \\
\text { aves alojadas }\end{array}$ & $\begin{array}{c}\text { Densidad animal } \\
\text { N. aves } / \mathrm{m}^{2}\end{array}$ \\
\hline Finca "San Luís Duitama & 24 & 175 & 7,3 \\
Finca "Piñalitos" Tibasosa & 12 & 100 & 8,33 \\
Finca "Buena Vista" Duitama & 8 & 60 & 7,5 \\
Finca "La Fuente" Santa Rosa de Viterbo & 27 & 200 & 7,4 \\
\hline
\end{tabular}


Tabla 2. Porcentaje de inclusión promedio y procedencia de los ingredientes utilizados en alimentación de pollo de engorde campesino en municipios de Boyacá, Colombia.

\begin{tabular}{ccc}
\hline Ingrediente & Porcentaje promedio de inclusion & Procedencia \\
\hline Alimento concentrado & 50 & Compra \\
Brócoli & 5 & Sobra de cultivos \\
Coliflor & 5 & Sobra de cultivos \\
Zanahoria & 5 & Sobra de cultivos \\
Maíz & 10 & Compra y sobra de cultivos \\
Alfalfa & 3 & Sobra de cultivos \\
Maralfalfa & 1 & Sobra de cultivos \\
Lechuga & 2 & Sobra de cultivos \\
Repollo & 5 & Sobra de cultivos \\
Lombriz & 8 & Cría en la finca \\
Melaza & 2 & Compra \\
Azola & 3 & Nacimiento en reservorios \\
Sal & 1 & Compra \\
\hline
\end{tabular}

En cuanto a la alimentación de las aves, ésta se realiza con materias primas de las propias fincas las cuales aportan hasta el $70 \%$ de los costos de producción; debido a que los municipios visitados producen cantidades de hortalizas, forrajes, tubérculos, granos, entre otros, los subproductos de estos cultivos son administrados a las aves de corral, disminuyendo el consumo de alimentos concentrados hasta en un 50\%, (Tablas 2 y 3 ).

La dieta de las aves hasta las dos primeras semanas de edad está basada en alimento concentrado, el cual se va disminuyendo y reemplazando por subproductos forrajeros de las propias fincas a medida que las aves se desarrollan. El suministro de subproductos de cosecha de las granjas como hortalizas, forraje, tubérculos, lombriz californiana, entre otros, inicia desde los 20 días de edad de los pollos hasta que completan un peso aproximado de 3,0 a $4,5 \mathrm{~kg}$ alcanzado a los 2,5 y 4,0 meses dependiendo del cuidado del productor. Estos subproductos son administrados en las horas de la mañana para estimular el consumo de las aves.

Una característica principal de los sistemas de cría avícola visitados en Boyacá, es la baja incidencia de enfermedades presentadas y la

Tabla 3. Consumo de alimento y peso promedio semanal de pollo de engorde en municipios de Boyacá, Colombia.

\begin{tabular}{cccc}
\hline Semana & $\begin{array}{c}\text { Consumo de alimento } \\
\text { en clima frío }(\mathrm{g})\end{array}$ & $\begin{array}{c}\text { Peso promedio } \\
\text { en clima frío }(\mathrm{g})\end{array}$ & $\begin{array}{c}\text { Conversion alimenticia } \\
\text { (kg alimento/kg peso) }\end{array}$ \\
\hline 1 & 131 & 140 & 0,936 \\
2 & 287 & 335 & 1,248 \\
3 & 476 & 650 & 1,375 \\
4 & 672 & 1040 & 1,506 \\
5 & 875 & 1455 & 1,678 \\
6 & 1085 & 1850 & 1,906 \\
7 & 1260 & 2250 & 2,127 \\
TOTAL & 4786 & 2250 & --- \\
\hline
\end{tabular}

FUENTE: Rodríguez (2000) 
poca utilización de productos farmacéuticos artificiales que disminuyen los costos de producción. Los pollos de engorde en estas explotaciones campesinas, son vacunados contra la enfermedad Newcastle en la segunda semana de vida, la vacuna contra la enfermedad Marek es administrada a los pollitos en incubadora. Los manejos sanitarios son preventivos, por ello es primordial el aseo y cuidado de las instalaciones y la comida y bebida suministrada a los animales; además, se les administra vermífugo en el agua mensualmente.

Las explotaciones avícolas campesinas de los municipios estudiados poseen la característica de postergar el engorde de los pollos hasta 70 días, debido, a que el crecimiento y desarrollo de las aves es más lento y en las últimas semanas se les proporciona más alimento forrajero para dar un sabor y contextura particular a la carne del ave. El peso promedio de sacrificio de las aves es variado, dependiendo de la cantidad y calidad nutritiva de la dieta; sin embargo, al terminar el ciclo de engorde los pollos presentan una contextura gruesa, patas completamente desarrolladas, cresta y patas pigmentadas, entre otras características las cuales dan una imagen del desarrollo completo y bienestar de los animales a sacrificar.

Por otro lado, los sistemas de producción de pollo de engorde campesino reflejan costos de inversión bajos, debido a la alta utilización de materiales reciclable, compra de pocos insumos, reducido consumo de alimentos concentrados y drogas en general, mano de obra familiar, entre otros factores que ayudan a amortiguar los costos de producción; lo anterior se refleja en una utilidad neta de $\$ 225.341$ y una rentabilidad de 29,20\%.
Desafortunadamente, el listado de labores diarias y registros de producción, sanidad e inversión no son llevados en forma ordenada ni archivada, lo que produce dificultad a la hora de estudiar más a fondo estos sistemas.

\section{Características de la producción de gallina} ponedora: al igual que la producción de pollo de engorde, este sistema de producción se maneja a baja escala y la mayoría de las fincas presentan al mismo tiempo producción de aves de postura y pollo de engorde. El consumo de huevo es alto en las familias campesinas, ya que sustituye en alguna medida las fuentes de proteína animal, además de ser vendidos rápidamente para generar ingresos adicionales.

En los sistemas avícolas visitados, el comienzo de la producción de huevo se estima entre las 20 y 22 semanas de edad, y se logran porcentajes de postura entre 80 y $90 \%$, con huevos de buena calidad y características como dureza de la cáscara y color de la yema deseable para los consumidores locales.

Las aves se mantienen en galpones en piso de tierra o con cama de viruta, forraje seco, entre otros materiales que la hacen confortable, además, las jaulas de postura no están implementadas por razones de costos y bienestar animal. Las instalaciones son construidas con materiales reciclables de las fincas, o compra de materiales de segunda para nidales, los cuales están construidos en madera o metal, en dimensiones suficientemente grandes para la comodidad de las aves. Las dimensiones y densidades de alojamiento se describen en la Tabla 4

Las aves son alimentadas exclusivamente con alimento comercial sin medicación ni pigmen-

Tabla 4. Dimensiones, número de aves alojadas y densidad animal de las instalaciones de gallina ponedora campesina en municipios de Boyacá, Colombia.

\begin{tabular}{lccc}
\hline & $\begin{array}{c}\text { Dimensión de las } \\
\text { Instalaciones }\left(\mathrm{m}^{2}\right)\end{array}$ & $\begin{array}{c}\text { Número de aves } \\
\text { alojadas }\end{array}$ & $\begin{array}{c}\text { Densidad animal } \\
\text { N. Aves } / \mathrm{m}^{2}\end{array}$ \\
\hline Finca "San Luís" Duitama & 10 & 25 & 2,5 \\
Finca "Piñalitos" Tibasosa & 40 & 80 & 2,0 \\
\hline
\end{tabular}


tos hasta la segunda semana de edad; a partir de allí se les suministran gradualmente subproductos de la finca como hortalizas, forraje, gusanos, larvas de moscas, entre otros que se pueden encontrar en piletas de desechos fecales de otras especies. Los ingredientes más utilizados y su porcentaje de inclusión se describen en la Tabla 5.

En estas explotaciones campesinas, el alimento concentrado es reemplazado gradualmente por subproductos de cosecha (hasta en un $50 \%)$, a medida que las aves desarrollan su sistema digestivo y aumenta la disponibilidad de subproductos por las cosechas recogidas. Esto disminuye los costos de producción mientras que las aves se mantienen en buena forma, no presentan señales de desgaste ni desnutrición y su porcentaje de postura es bueno.

Un factor importante a resaltar es la durabilidad de los porcentajes de posturas en las aves con este sistema, lo que representa más números de huevos para la venta (la cantidad de huevos producidos por gallina campesina por semana es de 5 huevos, es decir, 270 huevos en un periodo de 54 semanas). Además, debido a que los huevos son producidos por aves sin manejos artificiales ni sustancias toxicas resi- duales, son vendidos en las mismas fincas o en tiendas de barrio a precios de hasta $\$ 300$ la unidad, debido al color de la yema, sabor casero, gran tamaño y dureza de la cáscara, factores que los hacen deseables por los consumidores.

Los sistemas de producción de gallina ponedora campesina reflejan costos de inversión y producción más elevados que los de pollo de engorde, esto se debe al mayor número de aves criadas por los campesinos y por el tiempo de levante y producción de las mismas; sin embargo, es evidente que la alta utilización de materiales reciclables en las instalaciones amortigua los costos, así como el reducido consumo de alimentos concentrados, drogas en general, mano de obra de los mismos productores y la compra de pocos insumos no representan grandes sumas de dinero; lo anterior se refleja en una utilidad neta de $\$ 1.261 .479$ y una rentabilidad de $22,6 \%$.

\section{Propuesta de un modelo de producción de pollo de engorde y gallina ponedora alterna- tiva}

Los modelos de producción surgen como una necesidad para la integración de los animales

Tabla 5. Porcentaje de inclusión promedio y procedencia de los ingredientes utilizados en alimentación de gallina ponedora campesina en municipios de Boyacá, Colombia.

\begin{tabular}{ccc}
\hline Ingrediente & Porcentaje promedio de inclusión & Procedencia \\
\hline Alimento concentrado & 50 & Compra \\
Brócoli & 5 & Sobra de cultivos \\
Coliflor & 5 & Sobra de cultivos \\
Zanahoria & 4 & Sobra de cultivos \\
Maíz partido & 15 & Compra y sobra de cul- \\
Alfalfa & 4 & tivos \\
Repollo & 3 & Sobra de cultivos \\
Lombriz & 8 & Sobra de cultivos \\
Azola & 2 & Cría en la finca \\
Sal & 2 & Nacimiento en reservo- \\
rios \\
Cáscara de huevo molida & 1 & Compra \\
Sobras de cocina & 1 & Sobra de cocina \\
\hline
\end{tabular}


al medio ambiente, los sistemas de producción de pollo de engorde y gallina ponedora campesinos de Boyacá están siendo reducidos a confinamientos de baja y mediana densidad, aumentando la utilización de alimentos concentrados en las dietas básicas, para incrementar los porcentajes de producción y las ganancias económicas. Se describirán diferentes propuestas:

Cría de gallinas de postura en pastoreo: esta cría extensiva se justifica por dos razones: obtención de productos dirigidos a ciertos sectores de consumo que puedan acceder a artículos de mayor precio, y a complementarse con otras actividades de la granja, ya que estos modelos campesinos no constituyen la única fuente de ingresos económicos de las familias; además, estas explotaciones se caracterizan por poseer alojamientos simples, corrales en el exterior y alimentación variada.

Las instalaciones son variadas, dependen del número de aves a alojar, materiales disponibles y calidad del terreno; la Tabla 6 describe algunos parámetros importantes para alojar 100 aves.

La instalación 1 por su configuración "alargada” permite un reparto más homogéneo y cómodo para las aves en el interior del galpón y una mejor distribución de la ventilación local en épocas calurosas; además, de requerir pocos materiales de construcción, mano de obra y área pequeña de terreno. Su mayor desventaja es falta de rotación de potreros, lo cual conlleva a la acumulación de deyecciones en un pequeño terreno.

La instalación 2 presenta grandes ventajas en cuanto a la rotación de potreros, siembra de diversos forrajes conforme al tiempo de rotación, descanso de los mismos cuando no están ocupados, disminución de parásitos y vectores por la poca acumulación de deyecciones, comida variada para las aves por el aumento de la cantidad de materia orgánica y fuentes secundarias de proteína como gusanos, larvas, moscas, entre otros en los potreros ocupados. Las desventajas se reflejan en los costos de construcción de los corrales, ya que la mayor utilización de malla metálica y postes es evidente, además del incremento de la mano de obra para la rotación de las aves y el cultivo de forrajes en cada uno de los corrales; son mayores las necesidad de terreno. El tiempo de rotación de las aves dentro de los potreros puede variar entre 8 y 15 días dependiendo del número de aves y de la calidad y cantidad de la cubierta forrajera.

La instalación 3 presenta las mismas ventajas que la instalación 2 pero al poseer solo dos potreros hay poco tiempo de descanso de los mismos lo que podría impedir la siembra de algún forraje para suplementación alimenticia y la acumulación de patógenos y parásitos.

Los comederos y bebederos para estas instalaciones pueden ser construidos lineales y en tubos PVC u otro material de fácil limpieza con una

Tabla 6. Longitudes y densidades de algunos modelos de pastoreo para alojar 100 gallinas ponedoras campesinas en municipios de Boyacá, Colombia.

\begin{tabular}{cccc}
\hline Instalaciones & Longitudes $\mathrm{m}^{2}$ & $\begin{array}{c}\text { Densidad animal } \\
\text { N. aves } / \mathrm{m}^{2}\end{array}$ & Observaciones \\
\hline \multirow{2}{*}{1} & Potrero: 50 & Potrero: 2 & Sistema rectangular, con tres salidas para \\
& Gallinero: 13 & Gallinero: 8 & pastoreo, sin rotación de potreros \\
2 & Potrero: 66,6 & Potrero: 1,5 & Sistema con cuatro potreros, rotación de \\
& Gallinero: 20 & Gallinero: 5 & potreros, para mayor número de aves \\
3 & Potrero:50 & Potrero:2 & Sistema con dos potreros y rotación de \\
& Gallinero: 25 & Gallinero:4 & los mismos \\
\hline
\end{tabular}

Fuente: Cárdenas, 2004 
ubicación de uno por cada 25 aves cada 10 a 15 $\mathrm{cm}$ para los primeros, y uno por cada 50 aves con un espacio entre los mismos de 3 a $5 \mathrm{~cm}$ para los segundos. En cuanto a los ponederos, estos pueden ser de madera o plástico, recomendándose un nidal por cada 5 a 7 aves con una longitud de $35 \mathrm{~cm}$ de alto, $35 \mathrm{~cm}$ de fondo y $30 \mathrm{~cm}$ de frente, a una distancia del piso de 60 a $80 \mathrm{~cm}$.

Algunas recomendaciones adicionales incluyen, que los potreros en pastoreo no sean demasiado extensos, ya que las aves no utilizan la superficie total de los potreros, esto se debe a que las gallinas no suelen alejarse excesivamente del gallinero más allá de 60 a $70 \mathrm{~m}$. Estos potreros deben estar cubiertos por vegetación alta que no se emplee para otros fines y no tener matorrales que estimulen la "cloquez" o anidar sus huevos; además, deben tener una inclinación entre 5 y $10 \%$ para garantizar la evacuación de aguas lluvias y evitar las charcas contaminadas donde las aves pueden abrevar. El pastoreo debe ser luego de las 11:00 am, para estimular la postura en los nidales.

El manejo sanitario de las aves es primordial en estos sistemas de pastoreo, es recomendable aplicar las vacunas de New Castle, Bronquitis infecciosa, Gumboro y Viruela entre la semana 1 y 7 de edad, y el refuerzo de New Castle y Bronquitis infecciosa en las semanas 32 y 34 de edad. Además, los vermífugos deben ser administrados en forma preventiva en las semanas 10,14 y 35 de edad.
Para la alimentación de las aves se ha diseñado una dieta utilizando el método del tanteo, donde se utilizan los subproductos de cosecha más importantes en el departamento de Boyacá, y se pretende llenar todos los requerimientos nutricionales de las gallinas en su etapa de postura, esta se puede observar en las Tablas 7 y 8.

\section{Cría de pollos de engorde en pastoreo}

Este sistema no es usado en Boyacá frecuentemente para la cría de pollos de engorde, sin embargo, más allá del hecho de engordar pollos para la venta, hay que tener en claro las ventajas que su pastoreo tiene en terrenos desgastados y poco utilizados en las fincas de esta región, además, de la mejoría en la calidad organoléptica de la carne cuando las aves son producidas a un ritmo más lento y con alimentación variada como forrajes y subproductos de cosechas.

Las instalaciones de pollos de engorde son similares a las de gallina ponedora en pastoreo, ya que los modelos son aptos para ambas producciones, con una diferencia en las densidades. Sin embargo, los corrales en pastoreo para pollos de engorde suelen ser más pequeños con lo cual se evita la utilización de grandes terrenos y el ejercicio prolongado de los animales (galpón de 20 $\mathrm{m}^{2}$, potrero de $33 \mathrm{~m}^{2}$, densidad de 5 animales/ $\mathrm{m}^{2}$ en el galpón y 3 animales $/ \mathrm{m}^{2}$ en el potrero).

Los pollos de engorde deben ser obtenidos de 1 día de edad, llevarlos a las instalaciones don-

Tabla 7. Porcentaje de inclusión de los ingredientes para alimentación de aves de postura en municipios de Boyacá, Colombia.

\begin{tabular}{cc}
\hline Ingrediente & Porcentaje de Inclusión (\%) \\
\hline Alimento concentrado & 45 \\
Maíz quebrado & 20 \\
Trigo de segunda & 10 \\
Lombriz roja californiana & 10 \\
Alfalfa verde & 5 \\
Repollo & 2 \\
Lechuga & 2 \\
Zanahoria & 2 \\
Desechos de cocina & 4 \\
\hline
\end{tabular}

Fuente: Portela 1999 
Tabla 8. Porcentajes nutricionales totales de la dieta propuesta, comparados con los requerimientos nutricionales en aves de postura en producción en municipios de Boyacá, Colombia.

\begin{tabular}{ccccc}
\hline & Proteína \% & EM (Mcal) & Ca \% & P \% \\
\hline Requerimientos nutricionales aves en postura & 17 & 2.9 & 2.9 & 0,32 \\
Totales de dieta & 17,08 & 1,836 & 1,975 & 0,47 \\
\hline
\end{tabular}

Fuente: Barreto 2005

de pasarán todo su ciclo de vida y ofrecerles las comodidades que requieren para su desarrollo, entre las cuales se citan, calor (lámparas de luz o gas), agua, comida, esta última estará basada en alimento concentrado comercial hasta la segunda semana de edad, tiempo en el cual se va reduciendo paulatinamente el porcentaje de alimento concentrado y aumentando la inclusión de subproductos de la finca.

El manejo sanitario de los pollos, es un punto crítico en este tipo de explotaciones, las vacunas y vermifugaciones deben ser estrictamente instauradas, es decir, aplicación de vacunas como Marek, Gumboro y Bronquitis a la primera semana de edad, New Castle mas bronquitis en la segunda semana, refuerzo de New Castle a la tercera semana y refuerzo de Gumboro a la semana dos. La misma base de la alimentación para gallinas de postura se aplica para el pollo de engorde, partiendo del objetivo principal que es la introducción de subproductos de cosecha en la dieta de los animales y el reemplazo de gran parte del alimento concentrado (Tablas 9 y10 ).

Tabla 9. Ingredientes y porcentajes de inclusión en una dieta para pollo de engorde campesino en municipios de Boyacá, Colombia.

\begin{tabular}{cc}
\hline Ingrediente & $\begin{array}{c}\text { Porcentaje de } \\
\text { Inclusion }(\%)\end{array}$ \\
\hline Alimento concentrado & 50 \\
Maíz quebrado & 20 \\
Trigo de segunda & 5 \\
Lombriz roja californiana & 15 \\
Brócoli & 1 \\
Coliflor & 1 \\
Zanahoria & 2 \\
Feijoa & 2 \\
Desechos de cocina & 4 \\
\hline
\end{tabular}

Tabla 10 . Porcentajes nutricionales totales de la dieta, comparados con los requerimientos nutricionales en pollos de engorde en municipios de Boyacá, Colombia.

\begin{tabular}{lcccc}
\hline & $\begin{array}{c}\text { Proteína } \\
\%\end{array}$ & $\begin{array}{c}\mathrm{EM} \\
(\mathrm{Mcal})\end{array}$ & $\mathrm{Ca} \%$ & $\mathrm{P} \%$ \\
\hline $\begin{array}{c}\text { Requerimientos } \\
\text { nutricionales } \\
\text { pollo de }\end{array}$ & 20 & 3,1 & 0,9 & 0,35 \\
$\begin{array}{c}\text { engorde en } \\
\text { crecimiento* }\end{array}$ & & & & \\
Totales de dieta & 20,44 & 2,524 & 2,09 & 0,86 \\
\hline
\end{tabular}

Fuente: Barreto 2005

\section{Discusión y conclusiones}

A nivel mundial se observa que todos los países presentan explotaciones alternativas de pollo de engorde y gallina ponedora variadas, las cuales tienen diversos objetivos de acuerdo a las tendencias de dichos países. Sin embargo, aunque pareciera que estas producciones alternativas se han venido debilitando por el crecimiento de las producciones intensivas, la verdad es que han tomado fuerza gracias a la tendencia del consumo más saludable o ecológico (orientado a poblaciones con mayor poder adquisitivo) y cuidado del medio ambiente (regenerar pasturas para ganadería intensiva). Esto se refleja en países de Europa y Estados Unidos.

En los países latinoamericanos la situación es diferente; estas producciones son verdaderamente importantes en las familias campesinas quienes ven a los pollos de engorde y gallinas ponedoras como medios de alimentación y recursos económicos que sustentan sus necesidades básicas. Por ello se ha intentado conservar este tipo de producciones por medio de investigaciones y programas que garanticen buenos 
porcentajes de producción y calidad de los productos obtenidos.

Adicionalmente, en el afán de generar más productos (carne y huevos) en menos tiempo, en los países latinoamericanos se ha perdido gran parte de las riquezas genéticas avícolas y costumbres de producción, debido a la introducción de estirpes de alto rendimiento y alimentos concentrados a las producciones campesinas, las cuales deben aumentar sus gastos y cuidados animales para evitar la morbilidad y mortalidad en esta especie.

Los programas e investigaciones regionales que caractericen estos sistemas avícolas campesinos deben ser estimulados y conformados para recuperar parte de nuestras costumbres y riquezas genéticas y comenzar programas de mejoramiento que verdaderamente cuenten con los recursos de cada uno de los países.

Además de lo anterior, se concluyó que los sistemas campesinos de producción de pollo de engorde y gallina ponedora en los municipios de Duitama, Tibasosa y Santa Rosa de Viterbo presentan utilidades y rentabilidades favorables, debido a los reducidos costos de producción por el uso de subproductos de cosechas y materiales reciclables.

Es posible la introducción de subproductos alimenticios derivados de los cultivos de las propias fincas y la implementación de dietas balanceadas para cubrir los requerimientos nutricionales de las aves; sin embargo, se necesita más investigación sobre los valores nutricionales de muchos subproductos regionales, de los cuales se desconoce su aporte a la avicultura campesina.

El manejo sanitario de las explotaciones campesinas en Boyacá es deficiente, pues la administración del ciclo incompleto de vacunación y la baja utilización de vermífugos, evidencian la susceptibilidad de estas aves a contraer enfermedades.
Las explotaciones avícolas campesinas en el departamento de Boyacá, están siendo influenciadas por las explotaciones industriales, lo cual se demuestra por el confinamiento de las aves, dependencia de alimento concentrado, compra de productos automáticos, entre otros, los cuales aumentan los costos de producción y la dependencia de insumos que no se consiguen dentro de las fincas campesinas.

La información real sobre estos sistemas de explotación, es poca, por lo que muchos parámetros productivos son explicados y sostenidos con supuestos, pues algunas prácticas como las alimenticias no han sido probadas por métodos científicos que verifiquen realmente su viabilidad, esto deja al descubierto la necesidad de investigación en este sector y la propuesta de alternativas que verdaderamente aumenten la eficiencia productiva de las explotaciones campesinas a nivel nacional.

\section{Literatura citada}

Barreto, L. 2005. Módulo línea de profundización en sistema de producción avícola. Universidad Nacional Abierta y a Distancia. Bogotá.

Barrantes A., V.C. 2005. Análisis de la capacidad productiva y adaptativa de dos líneas genéticas de gallinas ponedoras (Sex Link e Isa Brown) bajo un sistema de pastoreo en el trópico húmedo. Universidad EARTH. Las Mercedes de Guácimo, Costa Rica.

Banco R., J.L. 2004. El estudio de la gallina ecológica. Escuela de Ingeniería de Técnicas Agrícola. Disponible en línea www.uclm.es/profesorado/produccionanimal/trabajos [Consulta: julio de 2011].

Carballo M., C.R. 2000. Manual de procedimientos para germinar granos para alimentación animal. Disponible en línea www.buscagro.com [Consulta: julio de 2001].

Chen, J., T. Lu, Tianshui \& Z. Han. 1997. Poultry production in China and the potential for 
using enzyme preparations. Disponible en línea http://www.eepsea.org/mimap/ev-30911201-1-DO_TOPIC.html [Consulta: junio de 2011].

Cuellar C., F.A. \& O. Garcia. 2007. Caracterización de sistemas de producción ecológicos en gallinas de línea ponedora "hy line brown" en la fundación granja "Los Pinos", municipio de Albania Santander. Tesis. Tunja, Facultad de Ciencias Agrarias, Universidad Pedagógica y Tecnológica de Colombia.

Fanático, A. 2002. Aves de corral sostenibles: resumen de producción. Disponible en línea www. attra.ncat.org [Consulta: julio de 2011].

FAO. 2002. Avicultura familiar. Roma.

Martínez, R. 2005. Hambre y desigualdad en los países andinos. La desnutrición y la vulnerabilidad alimentaria en Bolivia, Colombia, Ecuador y Perú. CEPAL. Santiago.

Moya A., R. 2004. Gallina de huevos azules: contribuciones a la elaboración de un protocolo. Publicaciones periódicas de CETSUR. Edición No. 4. Chile.

Muñoz, J. \& J. Vellojín. 2002. Diseño y evaluación de un sistema de producción de huevos con gallinas bajo pastoreo en el trópico húmedo. Uni- versidad EARTH. Guácimo de Limón, Costa Rica.

Pérez, A. \& C. Villa. 2002. La avicultura de traspatio en zonas campesinas de la provincia de Cuba. Universidad Central "Marta Abreu" de las Villas. Disponible en línea http://www.cipav.org. co [Consulta: julio de 2011].

Portela, R., I.H. Vélez \& E. Cassalett. 1999. Producción y manejo de proteína biológica para la alimentación de aves. Corpoica. Palmira, Colombia.

Posada H., E. \& E. Sánchez R. 2005. Comportamiento de algunas características productivas, estrés y resistencia a salmonella enteritidis en aves semipesadas en dos sistemas de producción. Veterinaria México 36(2): 205-215.

Torres, C. 2002. Las producciones ecológicas. En: XVII Curso de Especialización FEDNA. Escuela Superior de Ingenieros Agrónomos. Universidad Complutense. Madrid.

Turner, J. 1999. Ganadería industrial y medio ambiente. Compassion in World Farming Trust. Alicante, España.

Recibido: 04 de abril de 2011 Aceptado: 11 de junio de 2011 
